PROF. JESSICA ZUCMAN-ROSSI (Orcid ID : 0000-0002-5687-0334)

Article type : Original

\title{
Dual targeting of histone methyltransferase G9a and DNA-methyltransferase 1 for the treatment of experimental hepatocellular carcinoma
}

\begin{abstract}
Marina Bárcena-Varela ${ }^{1}$, Stefano Caruso², Susana Llerena ${ }^{3,4}$, Gloria Álvarez-Sola1,4, Iker Uriarte $^{1,4}$, M Ujue Latasa1, Raquel Urtasun'1, Sandra Rebouissou'2, Laura Alvarez ${ }^{1}$, Maddalen Jimenez ${ }^{1}$, Eva Santamaría 4 ,7, Carlos Rodriguez-Ortigosa ${ }^{1,4,7}$, Giuseppe Mazza5, Krista Rombouts5, Edurne San José-Eneriz ${ }^{6,7}$, Obdulia Rabal ${ }^{8}$, Xabier Agirre ${ }^{6,7}$, Maria Iraburu $^{9}$, Alvaro Santos-Laso ${ }^{9}$, Jesus M Banales ${ }^{4,9}$, Jessica Zucman-Rossi², Felipe Prósper6,7, Julen Oyarzabal' ${ }^{8}$, Carmen Berasain $^{1,4,7^{*}}$, Matías A Ávila1,4,7* , Maite G Fernández-Barrena ${ }^{1,4,7^{*}}$.
\end{abstract}

1. Hepatology Program. Cima-University of Navarra. Pamplona, Spain.

2. Functional Genomics of Solid Tumors, Inserm U1162, Université Paris Descartes, Université Paris Diderot, Université Paris 13, IUH, France.

3. Marqués de Valdecilla University Hospital. Santander, Spain.

4. CIBERehd, Instituto de Salud Carlos III, Madrid. Spain.

5. Institute for Liver and Digestive Health. University College London. London, UK.

6. Oncohematology Program. Cima-University of Navarra. Pamplona, Spain.

7. Instituto de Investigaciones Sanitarias de Navarra-IdiSNA. Pamplona, Spain.

8. Molecular Therapeutics Program. Cima-University of Navarra. Pamplona, Spain.

9. Department of Biochemistry and Genetics, University of Navarra. Pamplona, Spain.

10. Biodonostia Research Institute, Donostia University Hospital, Ikerbasque. San Sebastian, Spain.

${ }^{*} \mathrm{CB}, \mathrm{MAA}$ and MGF-B share senior authorship.

Key words: Liver cancer, epigenetic therapy, tumor metabolism, tumor-stroma interaction, differentiation therapy.

This article has been accepted for publication and undergone full peer review but has not been through the copyediting, typesetting, pagination and proofreading process, which may lead to differences between this version and the Version of Record. Please cite this article as doi: 10.1002/hep.30168

This article is protected by copyright. All rights reserved. 


\begin{tabular}{|c|c|}
\hline Marina Bárcena-Varela & mbarcena.1@alumni.unav.es \\
\hline Stefano Caruso & steno.caruso@gmail.com \\
\hline Susana Llerena & susanallerena@hotmail.com \\
\hline Gloria Alvarez-Sola & galvarez.1@alumni.unav.es \\
\hline Iker Uriarte & iuriarte@unav.es \\
\hline Maria Uxue Latasa & mulatasa@unav.es \\
\hline Raquel Urtasun & rurtasun@unav.es \\
\hline Sandra Rebouissou & sandra.rebouissou@inserm.fr \\
\hline Laura Alvarez & lalvarez5@unav.edu \\
\hline Maddalen Jimenez & mjomenez.9@alumni.unav.es \\
\hline Eva Santamaria & evasmaria@unav.es \\
\hline Carlos Rodriguez-Ortigosa & crodriguez@unav.es \\
\hline Giuseppe Mazza & Giuseppe.mazza.12@ucl.ac.uk \\
\hline Krista Rombouts & k.rombouts@ucl.ac.uk \\
\hline Edurne San Jose-Eneriz & esanjose@alumni.unav.es \\
\hline Obdulia Rabal & orabal@unav.es \\
\hline Xabier Agirre & xaguirre@unav.es \\
\hline Maria Iraburu & miraburu@unav.es \\
\hline Alvaro Santos-Laso & alvaro.santos@biodonostia.org \\
\hline Jesus M Banales & jesus.banales@biodonostia.org \\
\hline Jessica Zucman-Rossi & jessica.zucman-rossi@inserm.fr \\
\hline Felipe Prosper & fprosper@unav.es \\
\hline Julen Oyarzabal & julenoyarzabal@unav.es \\
\hline Carmen Berasain & cberasain@unav.es \\
\hline Matias A. Avila & maavila@unav.es \\
\hline Iaite G. Fernand & magarferc \\
\hline
\end{tabular}


Contact information. Prof. Matías A Avila or Dr. Maite G Fernández-Barrena. Program of Hepatology, CIMA-University of Navarra. Avda. Pio XII, n55. 31008. E-mail: maavila@unav.es, magarfer@unav.es. Phone: 34-948-194700. Fax: 34-948-194717.

Abbreviations. HCC, hepatocellular carcinoma; DNMT, DNA methyltransferase; HDAC, histone deacetylase; HMT, histone methyltransferase; EZH2, enhancer of zeste homolog-2; H3K9, histone 3 lysine 9; EHMT2, euchromatic histone-lysine methyltransferase-2; T, tumor tissue; NT, peritumoral human liver tissue; PBS, phosphate-buffered saline; DMEM, Dulbecco's Modified Eagle Medium; FBS, fetal bovine serum; HSC, hepatic stellate cell; IMDM, Iscove's Modified DMEM; PCR, polymerase chain reaction; UHRF1, ubiquitin-like with PHD and RING finger domains 1; DMSO, dimethylsulfoxide; CI, combination index; mRNA, messenger RNA; TNM, tumor, node, metastasis; siRNA, silencing RNA; 5meC, 5-methyl-cytosine; MDR1: multidrug resistance 1; GO, Gene Ontology; GSEA, Gene-Set Enrichment Analysis; E-CAD, Ecadherin; CYP7A1: cholesterol 7 $\alpha$-hydroxylase 7 $\alpha 1$; FBP1, fructose-1,6-bisphosphatase; GNMT, glycine-N-methyl transferase; MAT1A, methionine-adenosyltransferase 1A; qChIP, quantitative chromatin immunoprecipitation; GLUT1, glucose transporter-1; HK2, hexokinase-2; GPI, glucose-6-phosphate isomerase; ALDOA, aldolase A; PGK1, phosphoglycerate kinase-1; PKM2, pyruvate kinase-M2; LDHA, lactate dehydrogenase-A; VEGF, vascular endothelial growth factor; TGF $\beta$, transforming growth factor beta; $\operatorname{PPAR} \gamma$, peroxisome proliferator-activated receptor gamma; LRAT, lecithin-retinol acyltransferase; BAMBI, BMP and activin membrane-bound inhibitor; $\alpha$ SMA, alpha smooth muscle actin; COLI $\alpha 1$, procollagen I- $\alpha-1$; SKIL, SKI like protooncogene; TAGLN, transgelin; LOX, lysyl-oxidase; HIF, hypoxia-inducible factor.

Grant support. Grants SAF 2016-75972R, SAF2014-54191R and SAF 2017-88933R from Ministerio de Economía, Spain. Grant FIS PI16/01126, PI15/01132, and Miguel Servet Programme CON14/00129 to JMB, from Instituto de Salud Carlos III (ISCIII). "Ramón y Cajal-I3" contract to MUL, FPI Fellowship to MB-V and. Marie Curie EU contract to MGFB. Fundación La Caixa Hepacare Project; Fundación Eugenio Rodríguez Pascual; Fundación M. Torres; Fundación Fuentes Dutor; Fundación Mario Losantos; Fundación Familia PuigInfante; BiO-Eusko Fundazioa projects BIO15/CA/011 and BIO15/CA/016/BD. The generous support of Mr. Eduardo Avila and Mr. Sergio Durá is highly appreciated. J.Z-R group is supported by the Ligue Nationale contre le Cancer (Equipe Labellisée), Labex OncoImmunology (investissement d'avenir), Coup d'Elan de la Fondation BettencourtShueller, the SIRIC CARPEM and Fondation Mérieux. SC is supported by a CARPEM grant.

This article is protected by copyright. All rights reserved. 


\begin{abstract}
Epigenetic modifications like DNA and histone methylation functionally cooperate fostering tumor growth, including that of hepatocellular carcinoma (HCC). Pharmacological targeting of these mechanisms may open new therapeutic avenues. We aimed to determine the therapeutic efficacy and potential mechanism of action of our new dual G9a histone-methyltransferase and DNA-methytransferase 1 (DNMT1) inhibitor in human HCC cells and their crosstalk with fibrogenic cells. The expression of $G 9 a$ and $D N M T 1$, along with that of their molecular adaptor ubiquitin-like with PHD and RING finger domains-1 (UHRF1), was measured in human HCCs $(n=268)$, peritumoral tissues $(n=154)$ and HCC cell lines $(n=32)$. We evaluated the effect of individual and combined inhibition of G9a and DNMT1 on HCC cells growth by pharmacological and genetic approaches. The activity of our lead compound, CM-272, was examined in HCC cells under normoxia and hypoxia, human hepatic stellate cells and LX2 cells, and xenograft tumors formed by HCC or combined HCC+LX2 cells. We found a significant and correlative overexpression of G9a, DNMT1 and UHRF1 in HCCs in association with poor prognosis. Independent G9a and DNMT1 pharmacological targeting synergistically inhibited HCC cell growth. CM-272 potently reduced HCC and LX2 cells proliferation and quelled tumor growth, particularly in HCC+LX2 xenografts. Mechanistically, CM-272 inhibited the metabolic adaptation of HCC cells to hypoxia, and induced a differentiated phenotype in HCC and fibrogenic cells. The expression of the metabolic tumor suppressor gene fructose-1,6-bisphosphatase (FBP1), epigenetically repressed in HCC, was restored by CM-272. Conclusion. Combined targeting of G9a/DNMT1 with compounds like CM-272 is a promising strategy for HCC treatment. Our findings also underscore the potential of differentiation therapy in HCC.
\end{abstract}

Among primary liver cancers hepatocellular carcinoma (HCC) is the most frequent subtype and the second most common cause of cancer-related death(1). HCC commonly arise amidst an intricate crosstalk between cancer, angiogenic, inflammatory and fibroblastic cells in a hypoxic milieu fostering tumor growth(2). HCCs are molecularly heterogeneous tumors(3), and this heterogeneity may underlie the limited success of conventional and targeted chemotherapies This article is protected by copyright. All rights reserved. 
tested in HCC patients(1), with systemic treatment options currently limited to the multikinase inhibitors sorafenib and regorafenib(4,5). Although these agents do improve patients' survival, therapies targeting growth factor signaling have shown limited success(1) and novel approaches for HCC treatment must be pursued. The promising results of emerging immunotherapies illustrate the potential of exploring alternative avenues for HCC treatment(6).

Up to $50 \%$ of HCCs harbor alterations in the epigenetic machineries, suggesting a profound reshape in the epigenome as a hallmark of HCC(7). Global genomic DNA hypomethylation is characteristic of HCC. This is accompanied by locus-specific hypermethylation and silencing of putative tumor suppressor genes in association with abnormal expression of the DNA methyltransferases DNMT1, DNMT3a and DNMT3b(8). These alterations contribute to the pathogenesis and prognosis of HCC from early stages of the disease(9), and targeting aberrant DNA methylation using DNMT inhibitors is currently being explored(10). Other epigenetic alterations found in HCC include reversible changes in the post-translational modification of histones, such as acetylation or methylation of lysine residues, which may occur in genomewide and gene-specific manners(8). Dysregulation of histone-modifying enzymes like histone deacetylases (HDACs) and histone methyltransferases (HMTs) has been also reported in HCC, with elevated expression of class I and III HDACs, and HMTs such as enhancer of zeste homolog2 (EZH2), impacting on HCC progression(8,11). Some drugs targeting these epigenetic modifiers have been tested in clinical trials with promising results(12). However, epigenetic regulation is a complex process with different effectors such as DNMTs and HMTs cooperating in chromatin remodeling and gene expression control(13). In this sense, several studies have shown how DNA methylation and histone H3 methylation at lysine 9 (H3K9) engage in an epigenetic conversation where methylation information is "translated" from histone to DNA and vice versa(13,14). H3K9 mono- and dimethylation is catalyzed by the HMT G9a, also known as euchromatic histone-lysine methyltransferase 2 (EHMT2)(15). G9a physically interacts with

This article is protected by copyright. All rights reserved. 
DNMT1, contributing to DNA methylation during cell replication(16). G9a expression is dysregulated in cancer contributing to cell growth, survival, adaptation to hypoxia and metastasis(15). Very recently G9a was shown to be up-regulated and to promote HCC progression(17). In agreement with the functional interaction between DNMT1 and G9a, both DNA and H3K9 methylation have been linked to tumor suppressor gene silencing and cancer cell proliferation(18). Therefore, we hypothesized that simultaneous targeting of G9a and DNMTs methyltransferase activity could be a more effective strategy in HCC therapy.

We recently reported the development of potent first-in-class, selective and reversible dual small molecule inhibitors against G9a and DNMTs activity, demonstrating their efficacy in hematological malignancies(19). Here we show the potential therapeutic value of this type of molecules in experimental models of HCC.

\section{Materials and Methods}

\section{Human samples}

A cohort of 268 liver tumor samples (T), 154 peritumoral liver samples (NT) and 5 samples of normal liver tissues were collected from patients surgically treated in Bordeaux and Créteil hospitals in France. The study was approved by institutional review board committees (CCPRB Paris Saint-Louis, 1997, 2004, and 2010, \#01-037; Bordeaux \#2010-A00498-31). Written informed consent was obtained in accordance with French legislation. These patients and samples have been described previously(20-22) and are summarized in Supplementary Table

1.

This article is protected by copyright. All rights reserved. 


\section{Mouse xenograft models}

The subcutaneous tumor model was established injecting 10x106 of PLC/PRF5 or HepG2 cells, or $5 \times 10^{6} \mathrm{PLC} / \mathrm{PRF} 5$ cells plus $5 \times 10^{6} \mathrm{LX} 2$ cells, on the right flank region of male athymic nude mice (6-8 weeks)(Envigo, Valencia, Spain). When tumors reached $\sim 100 \mathrm{~mm}^{3}$, mice $(\mathrm{n}=6)$ were randomized into control and treatment groups. Orthotopic xenografts are described in Supplementary Materials and Methods. Mice received $5 \mathrm{mg} / \mathrm{kg}$ (i.p.) of CM-272 or same volume of vehicle (phosphate-buffered saline, PBS), for the indicated times. This dose was selected based on our previous studies(19). At the end of treatment tumors were harvested, fixed with $4 \%$ formalin for histological analyses or snap-frozen and stored at $-80^{\circ} \mathrm{C}$.

\section{Cell lines and human hepatic stellate cells (hHSCs)}

The origin and culture of the 32 HCC cell lines used in this study has been previously described(23). The human HSC line LX2 (Millipore-Merck, Darmstadt, Germany), was cultured in DMEM supplemented with 2\% FBS and antibiotics. Primary hHSCs were isolated from resected liver wedges obtained from patients undergoing surgery at the Royal Free Hospital (London, UK) after giving informed consent (\#EC01.14-RF). Isolation, purity and culture of hHSCs were as published(24). Experiments were performed on hHSCs from at least three independent cell preparations, used between passages 3-8. For hypoxic culture conditions cells were incubated under $1 \% \mathrm{O}_{2}$ atmosphere in the $\mathrm{H} 35$ Hypoxystation incubator (Don Whitley Scientific Ltd., Shipley, UK).

\section{Cell proliferation assay}

Cells were seeded at a density of 2500-3000 cells/well in 96-well plates (triplicates). After overnight incubation, cells were treated for $48 \mathrm{~h}$ with vehicle alone (0.1\% DMSO) or with CM-

This article is protected by copyright. All rights reserved. 
272 in complete medium. Experiments were repeated three times for each cell line. Cell viability was measured using the CellTiter 96 Aqueous One Solution Cell Proliferation Assay (Promega, Madison, WI). The concentration of drug inhibiting cell growth by $50 \%$ relative to the untreated control $\left(\mathrm{GI}_{50}\right)$ was calculated after curve fitting with GraphPad-Prism-v5 software as described(19).

\section{Combination assays}

For the calculation of combination index (CI) values, growth inhibition was determined at different concentrations of the G9a inhibitor (BIX-01294) in combination with different concentrations of the DNMT inhibitor decitabine (5-aza-2'-deoxycytidine) (Sigma, St. Louis, MO). Briefly, 3000 cells were cultured in a 96-well plate in triplicates and the different concentrations of compounds were added in a final volume of $100 \mu \mathrm{L}$. After $48 \mathrm{~h}$ viability was measured using the Cell Titer 96 Aqueous One Solution Cell Proliferation Assay. Data were analyzed using the Calcusyn software (Biosoft, Cambridge, UK)(19), and the combination index (CI) determined whether the effects of drug combinations were additive ( $\mathrm{CI}=1$ ) or synergistic $(\mathrm{CI}<1)$.

\section{Statistical Analysis}

Human samples data visualization and statistical analyses were performed using R software version 3.3.2 (R Foundation for Statistical Computing, Vienna, Austria. https://www.Rproject.org) and Bioconductor packages. Comparison of the different gene expression levels between groups were evaluated using Mann-Whitney U test or Kruskal-Wallis Test. Spearman correlation analysis was used to test the association between continuous variables. Univariate survival analysis was performed using Kaplan-Meier curve with log-rank test. The median $69 A$,

This article is protected by copyright. All rights reserved. 
DNMT1 and UHRF1 expression levels on the total number of analyzed samples was used to determine the low- and high- expression groups. For the rest of the data the statistical analysis was performed using GraphPad Prism-v5 program. For comparison between two groups, parametric Student t test was used. All reported $P$ values were two-tailed and differences were considered significant when $P<.05$.

Additional methods are provided as supplementary material.

\section{Results}

\section{Expression of G9a, DNMT1 and the DNA methylation regulator UHRF1 in human HCC}

We first examined the expression of G9a and DNMT1 in normal liver tissues (n=5), peritumor non-transformed liver tissues (NT, $n=154)$ and tumor liver tissues $(\mathrm{T}, \mathrm{n}=268)$ (Supplementary

Table 1). Consistently with recent(17) and previous observations(25) G9a and DNMT1 expression was significantly elevated in HCC tissues (Fig. 1A). Ubiquitin-like with PHD and RING finger domains 1 (UHRF1) is an essential regulator of DNA methylation during DNA replication, and an adaptor in the crosstalk between DNA and histone methylation, overexpressed in many tumors including HCCs $(16,26)$. We also found high mRNA levels of UHRF1 in our HCC samples (Fig. 1A). Notably, we observed a significant positive correlation between the expression of G9a and DNMT1, G9a and UHRF1, as well as DNMT1 and UHRF1 across HCC samples (Fig. 1B). Some of us recently described a molecular signature based on the expression of 5 genes that accurately identified patients with aggressive tumors and a poor prognosis(27). We found that G9a, DNMT1 and UHRF1 expression was significantly higher in HCC tissues from patients classified as poor prognostic group (P2) by this signature (Fig. 1C). Previous transcriptomic analyses classified HCCs in six subgroups, G1 to G6, with worse survival for patients within subgroups G1-G3(28). We found highest levels of G9a, DNMT1 and UHRF1 expression in samples within groups G1-G3 (Fig. 1C). G9a, DNMT1 and UHRF1 expression was

This article is protected by copyright. All rights reserved. 
also higher in HCC tissues displaying macroscopic vascular invasion, and patients with more advanced Edmondson grades and "tumor, node, metastasis" (TNM) stages (Fig. 1C). Finally, patients with high $G 9 a$ and DNMT1 mRNA levels showed worse survival, and a similar trend was observed for UHRF1 (Fig. 1D).

\section{Dual targeting of G9a and DNMT1 in HCC cells in vitro and in vivo}

We examined G9a, DNMT1 and UHRF1 expression in a wide panel of human HCC cell lines, finding significantly higher levels compared to normal and peritumoral liver tissues (Fig. 2A). G9a, DNMT1 and UHRF1 protein levels were consistently higher in four representative HCC cell lines compared to primary human hepatocytes (Fig. 2B). Interestingly, we also found a significant positive correlation between $G 9 a$ and DNMT1 mRNA levels and between UHRF1 and DNMT1 mRNA levels, while that between G9a and UHRF1 showed a positive trend (Fig. 2C). To demonstrate that simultaneous inhibition of G9a and DNMT1 could be an improved strategy to quell HCC cell growth, we tested the effect of $G 9 a$ and $D N M T 1$ gene expression knockdown on HCC cell viability. Transfection with siRNAs specific for G9a or DNMT1 (Supplementary Fig. 1) reduced HepG2 and PLC/PRF5 cells survival, and the combinatory effect of both siRNAs was additive (Fig. 2D). Next, we treated HepG2 and PLC/PRF5 cells with a G9a inhibitor (BIX01294) and the DNMT inhibitor decitabine. This combination showed a synergistic inhibition on HCC cells growth at all concentrations tested (Fig. 2E). We subsequently evaluated the antiproliferative effects of CM-272, our lead G9a/DNMT1 inhibitory compound(19), in a panel of HCC cell lines. CM-272 GI 50 was in the nM range for most HCC cell lines (Fig. 3A). Interestingly, the observed $\mathrm{GI}_{50}$ values directly correlated with the expression of $A B C B 1$ (Supplementary Fig. 2A), the gene coding for the drug efflux pump MDR1, a major determinant of tumor cells drug sensitivity. The relevance of this finding was supported by the demonstration that CM-272 is indeed a substrate of MDR1 (Supplementary Fig. 2B). CM-272 decreased total levels of H3K9me2 and DNA methylation (5-methyl-cytosine, 5meC) (Fig. 3B), while other epigenetic histone marks were not inhibited (Supplementary Fig. 2C).

This article is protected by copyright. All rights reserved. 
Interestingly, a significant reduction of G9a, DNMT1 and UHRF1 protein levels was found in CM272-treated cells (Fig 3B). However, at the mRNA level this effect was only observed for UHRF1 in HepG2 cells (Supplementary Fig. 2D). CM-272 also markedly impaired the clonogenic capacity of HCC cells (Fig. 3C).

Next, we examined the in vivo antitumoral properties of CM-272. PLC/PRF5 cells were subcutaneously injected into nude mice and, when tumors reached $100 \mathrm{~mm}^{3}$, mice were treated with CM-272. Tumor growth was significantly reduced and tumor weights at the end of treatment were also lower (Fig. 3D). Similar results were obtained in HepG2 subcutaneous xenografts (Supplementary Fig. 3A), and on the growth of PLC/PRF5 cells tumors orthotopically implanted in the livers of nude mice (Fig. 3E, Supplementary Fig. 4A). In agreement with our previous study(19) we did not observe any signs of toxicity in CM-272 treated animals (Supplementary Fig. 3B and C) and mice weights were normal at the end of treatment (data not shown). Interestingly, serum CM-272 concentrations in treated mice were in the range of its $\mathrm{GI}_{50}$ as determined at the end of treatments (Supplementary Fig. 4B).

\section{Mechanisms of CM-272 antitumoral activity in HCC cells}

To gain insight into the mechanisms of the antitumoral effect of CM-272 we performed a microarray analysis of gene expression in HepG2 cells. We detected 388 upregulated and 509 downregulated genes compared to controls $(P<.01)$. Gene ontology $(\mathrm{GO})$ functional classification of differentially expressed genes identified general categories linked to the regulation of cell growth and proliferation, and to the interaction with the cellular microenvironment (Fig. 4A). Microarray gene expression data scrutiny using gene-set enrichment analysis (GSEA) revealed categories related to cell proliferation, metastasis, growth factor signaling, hypoxic response, and interaction with the microenvironment

(Supplementary Table 3), showing negative enrichment in CM-272 treated cells. Among these gene-sets we found signatures characteristic of more aggressive HCC subclasses, such as the G1This article is protected by copyright. All rights reserved. 
G3 subgroups identified by Boyault el al.(28), and the S2 subclass from Hoshida et al.(29) (Fig. 4B). Remarkably, one of the gene-sets with strong positive enrichment encompassed the genes defining the human liver-specific transcriptome, abundant in metabolic genes(30) (Fig. 4B).

These findings suggested that enhanced G9a and DNMT1 activities contribute to the growth of HCC cells and to their interaction with the extracellular milieu, but also evidenced their strong negative impact on the expression of metabolic genes characteristic of the differentiated hepatocyte. Consistently, we found that treatment of HepG2 cells with CM-272 resulted in the upregulation of the epithelial marker E-cadherin $(E-C A D)(31)$. Similarly, the enzymes cholesterol $7 \alpha$-hydroxylase-1 (CYP7A1), fructose-1,6-bisphosphatase (FBP1), glycine-N-methyl transferase (GNMT) and methionine-adenosyltransferase 1A (MAT1A), involved in key liver metabolic functions were also induced (Fig. 4C). qChIP analyses showed a decrease in H3K9me2 levels in GNMT, CYP7A1 and FBP1 genes promoters upon CM-272 treatment (Fig. 4D). FBP1, the rate limiting enzyme in gluconeogenesis, is a tumor suppressor gene and its expression is reduced in HCC (Supplementary Fig. 5A) in association with molecular and clinical characteristics of tumor aggresiveness (Supplementary Fig. 5B) as previosuly described(32). Interestingly, we found a statistically significant negative correlation between FBP1 and G9a or UHRF1 mRNA levels in our set of HCC samples, and a similar trend with DNMT1 mRNA levels (Supplementary Fig. 5C). Downregulation of FBP1 expression is attributed to promoter hypermethylation(32). Consistently, we observed loss of DNA methylation in FBP1 promoter region after CM-272 or decitabine treatment, as analyzed by methylation-specific PCR (MSP) or DNA pyrosequencing (Fig. 4E). The efficacy of CM-272 on DNA demethylation was also validated on RASSF1 (Supplementary Fig. 5D) another gene frequently hypermethylated in HCC(9). Reduced FBP1 expression stimulates tumor progression by enhancing glucose metabolism to lactate(32), a process called aerobic glycolysis that provides selective advantages for cancer cell proliferation(33). Interestingly, we found that CM272 reduced glucose consumption and lactate production in HepG2 cells (Fig. 4F).

This article is protected by copyright. All rights reserved. 


\section{CM-272 inhibits the growth and metabolic adaptation of HCC cells to hypoxia.}

In solid tumors like HCC glycolysis is exacerbated by the pro-tumorigenic hypoxic environment(34). As recently found in breast cancer cells(35), we observed that G9a protein levels were increased in HCC cells under hypoxia (Fig. 5A and Supplementary Fig. 4A). We found that the hypoxia-stimulated growth of HCC cells(36) was markedly reduced by CM-272 (Fig. 5B and Supplementary Fig. 4B). This effect was reproduced upon $G 9 a$ expression knockdown, while, conversely, $G 9 a$ overexpression enhanced hypoxia-stimulated cell proliferation (Supplementary Fig. 4C). Next, we examined the effects of CM-272 on the expression of key glycolytic enzymes triggered by hypoxia and also upregulated in HCC: glucose transporter-1 (GLUT1), hexokinase-2 (HK2), glucose-6-phosphate isomerase (GPI), aldolase A (ALDOA), phosphoglycerate kinase-1 (PGK1), pyruvate kinase-M2 (PKM2) and lactate dehydrogenase-A $(L D H A)(37)$. The expression of all these genes was markedly reduced by CM272 (Fig. 5C) and, consistently, lactate production was inhibited by CM-272 (Fig. 5D). Hypoxia also fosters HCC development through the stimulation of angiogenesis and liver fibrosis(38). Therefore, we evaluated the effects of CM-272 on the expression of the pro-angiogenic and profibrogenic factors vascular endothelial growth factor (VEGF) and transforming growth factor- $\beta$ (TGF $\beta$ ). We found that CM-272 significantly inhibited hypoxia-triggered $V E G F$ and TGF $\beta$ expression (Fig. 5E). The key role played by G9a in $V E G F$ and $T G F \beta$ expression was further supported by experiments in which G9a expression was knocked down (siRNA transfection) or enhanced (G9a cDNA transfection) in HCC cells (Fig. 5E).

\section{CM-272 inhibits the proliferation and activation of human hepatic stellate cells}

Epigenetic events control fibrogenic cell activation and the fibrotic stroma contributes to HCC development(39). This, together with the CM-272-mediated inhibition TGF $\beta$ and VEGF expression in HCC cells, prompted us to examine CM-272 effects on human hepatic stellate cells

This article is protected by copyright. All rights reserved. 
(hHSCs). We found that CM-272 dose-dependently inhibited the proliferation of human liver myofibroblasts LX2 cells (Fig. 6A). To better understand the effects of CM-272 in liver fibrogenic cells we performed a microarray analysis of gene expression in LX2. We detected 1549 upregulated and 1702 downregulated genes $(P<.01)$, and GO functional classification fundamentally identified categories related to HSC metabolic differentiation (e.g. vitamin A metabolism) and their response to activating stimuli (Fig. 6B). Accordingly, when we applied GSEA we found significant enrichment in categories associated with metabolic functions, signal transduction and cell proliferation (Supplementary Table 4). Particularly interesting was the positive enrichment in genes of the KEGG Retinol Metabolism gene-set, and the negative enrichment in genes from the Signaling by TGF $\beta$ Receptor Complex Reactome gene-set (Fig. 6C). Upregulation of genes associated with quiescent and differentiated HSCs, such as peroxisome proliferator-activated receptor $\gamma(P P A R \gamma)$, lecithin-retinol acyltransferase (LRAT) and BMP-activin membrane-bound inhibitor (BAMBI) was validated in CM-272 treated LX2 cells and primary hHSCs (Fig. 6D). Consistently, CM-272 treatment reduced the levels of H3K9me2 and DNA methylation at the PPAR $\gamma$ promoter in LX2 cells (Fig. 6E). We also demonstrated the inhibitory effects of CM-272 on TGF $\beta$-activated gene expression in both cell types (Fig. 6F and Supplementary Fig. 7).

\section{CM-272 potently inhibits the in vivo growth of HCC driven by LX2 cells}

Activated HSCs markedly influence HCC progression, therefore targeting the tumor-stroma crosstalk may identify improved therapeutic strategies(40). Thus, we evaluated CM-272 antitumoral activity on xenografts in which PLC/PRF5 cells were co-injected with LX2 myofibroblasts in nude mice. As expected, growth of PLC/PRF5 tumors was significantly enhanced by LX2 cells (Fig. 7A). CM-272 treatment resulted in a marked inhibition of PLC/PRF5-LX2 mixed tumors (Fig. 7B). Tumor vascularization (CD31 staining) was also reduced by CM-272 (Fig. 7C and Supplementary Fig. 5A). Consistent with our in vitro This article is protected by copyright. All rights reserved. 
observations, CM-272 downregulated G9a expression and strongly influenced tumor cells phenotype in vivo. Indeed, CM-272 inhibited the expression of the glycolysis driver HK2, while that of GNMT and FBP1 was upregulated (Fig. 7D). These effects were recapitulated in xenografts generated with PLC/PRF5 cells alone (Fig. 3A and Supplementary Fig. 5B).

\section{Discussion}

Epigenetic mechanisms are emerging as attractive therapeutic targets in solid tumors and epigenetic drugs are already being tested in HCC clinical trials(10). However, the extensive functional crosstalk between chromatin marks such as DNA and H3K9 methylation(13), suggests that simultaneous targeting of different epigenetic modifiers may improve therapeutic efficacy. We recently demonstrated this contention by showing the remarkable antitumoral activity of CM-272, a dual G9a/DNMT1 inhibitor, in different hematological neoplasms(19). Now we provide evidence supporting the potential of combined G9a/DNMT1 antagonism for HCC treatment.

First, we demonstrated the coordinated overexpression of $G 9 a$ and DNMT1, along with their key adaptor UHRF1(16,26), in human HCC tissues. The pathophysiological relevance of this matched overexpression is suggested by its significant association with molecular, histological and clinical characteristics indicative of aggressive disease and poor prognosis $(27,28)$. The rationale for the simultaneous inhibition of G9a/DNMT1 in HCC was further established by the synergistic anti-proliferative action of combined G9a and DNMT1 specific antagonists. Thus, CM-272 exerted a very potent antiproliferative effect in a wide panel of human HCC cell lines, which also showed a close correlation in the expression of $G 9 a, D N M T 1$ and the UHRF1 adaptor. Interestingly, $\mathrm{CM}-272 \mathrm{GI}_{50}$ values found in $\mathrm{HCC}$ cell lines also directly correlated with the expression levels of the drug efflux pump $A B C B 1$ (MDR1), and we could demonstrate that CM-

This article is protected by copyright. All rights reserved. 
272 is a substrate for this membrane transporter. These findings suggest that inhibition of MDR1 could further enhance the therapeutic efficacy of CM-272. CM-272 inhibited HCC cells growth in vivo in the absence of apparent toxicity. The high specificity of CM-272 for G9a/DNMT1, and a mechanism of action based on the reversible inhibition of G9a and DNMT1 binding to their substrates, but not to S-adenosylmethionine(19), may contribute to explain its lack of off-target effects and systemic toxicity.

One relevant finding was the downregulation of G9a protein levels in HCC cells and xenograft tumors upon CM-272 treatment. This response is coherent with previous studies describing the proteosomal degradation of other histone-methyltransferases (e.g. EZH2) after inhibition of their catalytic activity(41). Reduction of G9a levels may be significant to the antitumoral effects of CM-272, as G9a has been described also as a transcriptional coactivator of cancer-related genes independently of its catalytic activity(42). The concomitant downregulation of DNMT1 and UHRF1 proteins upon CM-272 treatment found in HCC cells could be secondary to G9a depletion, as all these proteins physically interact in multimeric functional complexes that may mediate the relative stability of their components $(13-16,18)$. Nevertheless, this issue merits further investigation.

The mechanisms of CM-272 antitumoral action are likely multifarious. However, the growth inhibitory effects of CM-272 on HCC cells were not accompanied by the induction of apoptosis or autophagy (data not shown). In this regard, our transcriptomic analyses provided valuable mechanistic insights. Very interestingly, the downregulation of growth and proliferation-related genes was accompanied by the induction of genes characteristic of the adult and differentiated hepatocyte. The reactivation of E-cadherin expression by CM-272 may contribute to restore an epithelial and less malignant phenotype, and is consistent with G9a and DNA methylationmediated $E-C A D$ repression in breast cancer(43). However, perhaps more compelling was the reactivation of genes involved in central metabolic pathways, such as one-carbon metabolism

This article is protected by copyright. All rights reserved. 
and gluconeogenesis, which are epigenetically repressed during

hepatocarcinogenesis $(32,44,45)$. Reprogramming of metabolism is a hallmark of neoplastic transformation, and this alteration is particularly extensive in a metabolic organ like the liver(37). Rewiring of glucose metabolism, including the repression of gluconeogenic enzymes and the activation of specific glycolytic isozymes, contributes to fulfil the tumor anabolic demands particularly in its hypoxic core(37). We found that CM-272 potently counteracted these responses. Reactivation of $F B P 1$ expression may be a key mechanism, as loss of $F B P 1$ expression by promoter methylation activates the tumoral glycolytic program and enhances tumoral growth(32). Moreover, FBP1 has been recently reported to directly inhibit the activity of hypoxia-inducible factors in renal cancer cells in a catalytic activity-independent manner(46). This function of FBP1 may be also related to the overall impairment of HCC cells adaptation to hypoxia elicited by CM-272, including the blunted expression of protumorigenic factors like $V E G F$ and TGF $\beta$.

Epigenetic mechanisms, including coordinated DNA and histone methylation, have emerged as central events in the transcriptomic reprogramming of quiescent to activated HSCs(39). Our microarray analyses suggested that CM-272 returned the myofibroblastic transcriptomic phenotype of HSCs towards a more differentiated adipogenic one(47). Although the underlying mechanisms need further elucidation, the positive effect on PPAR $\gamma$ expression may be significant. Indeed, PPAR $\gamma$ is a transcriptional suppressor of HSC fibrogenic activation, able to maintain quiescence and vitamin-A metabolism(39). Moreover, PPAR $\gamma$ expression is transcriptionally silenced during HSC activation through mechanisms involving DNA and H3K9 hypermethylation(48), and these epigenetic marks were reversed by CM-272 treatment. On the other hand, CM-272-mediated upregulation of $B A M B I$, a TGF $\beta$ pseudoreceptor and negative regulator of HSC activation(49), could partially account for the blunted response to TGF $\beta$ of key

This article is protected by copyright. All rights reserved. 
fibrogenic genes. The functional relevance of these CM-272-mediated effects was demonstrated by the remarkable inhibition of the growth of mixed HCC-LX2 xenografts.

Summing up, we have provided evidence supporting the therapeutic efficacy of dual G9a/DNMT1 targeting for the treatment of HCC with novel first-in-class reversible inhibitors. Mechanistically, our study indicates that CM-272 can induce HCC and HSC cell differentiation and growth inhibition, underscoring the potential of differentiation therapy (50) in liver cancer, and provides a rationale for combination with other anticancer agents with different mechanisms of action (Fig. 8).

\section{References}

1. Gerbes A, Zoulim F, Tilg H, Dufour J-F, Bruix J, Paradis V, et al. Gut roundtable meeting paper: selected recent advances in hepatocellular carcinoma. Gut. 2018;67:380-388.

2. Giannelli G, Rani B, Dituri F, Cao Y, Palasciano G. Moving towards personalised therapy in patients with hepatocellular carcinoma: the role of the microenvironment. Gut. 2014;63:1668-1676.

3. Zucman-Rossi J, Villanueva A, Nault J-C, Llovet JM. Genetic Landscape and Biomarkers of Hepatocellular Carcinoma. Gastroenterology. 2015;149:1226-1239.e4.

4. Llovet JM, Ricci S, Mazzaferro V, Hilgard P, Gane E, Blanc J-F, et al. Sorafenib in advanced hepatocellular carcinoma. N. Engl. J. Med. 2008;359:378-390.

5. Bruix J, Qin S, Merle P, Granito A, Huang Y-H, Bodoky G, et al. Regorafenib for patients with hepatocellular carcinoma who progressed on sorafenib treatment (RESORCE): a randomised, double-blind, placebo-controlled, phase 3 trial. Lancet. 2017;389:56-66.

6. El-Khoueiry AB, Sangro B, Yau T, Crocenzi TS, Kudo M, Hsu C, et al. Nivolumab in patients with advanced hepatocellular carcinoma (CheckMate 040): an open-label, noncomparative, phase 1/2 dose escalation and expansion trial. Lancet. 2017;389:24922502.

7. Zhang Z. Genomic landscape of liver cancer. Nat. Genet. 2012;44:1075-1077.

8. Pogribny IP, Rusyn I. Role of epigenetic aberrations in the development and progression of human hepatocellular carcinoma. Cancer Lett. 2014;342:223-230.

This article is protected by copyright. All rights reserved. 
9. Villanueva A, Portela A, Sayols S, Battiston C, Hoshida Y, Mendez-Gonzalez J, et al. DNA methylation-based prognosis and epidrivers in hepatocellular carcinoma. Hepatology. 2015;61:1945-1956.

10. Hardy T, Mann DA. Epigenetics in liver disease: from biology to therapeutics. Gut. 2016;65:1895-1905.

11. Chiba T, Saito T, Yuki K, Zen Y, Koide S, Kanogawa N, et al. Histone lysine methyltransferase SUV39H1 is a potent target for epigenetic therapy of hepatocellular carcinoma. Int. J. Cancer. 2015;136:289-298.

12. Bitzer M, Horger M, Giannini EG, Ganten TM, Worns MA, Siveke JT, et al. Resminostat plus sorafenib as second-line therapy of advanced hepatocellular carcinoma - The SHELTER study. Journal of Hepatology. 2016;65:280-288.

13. Du J, Johnson LM, Jacobsen SE, Patel DJ. DNA methylation pathways and their crosstalk with histone methylation. Nat Rev Mol Cell Biol. 2015;16:519-532.

14. Tachibana M, Matsumura Y, Fukuda M, Kimura H, Shinkai Y. G9a/GLP complexes independently mediate H3K9 and DNA methylation to silence transcription. EMBO J. 2008;27:2681-2690.

15. Casciello F, Windloch K, Gannon F, Lee JS. Functional Role of G9a Histone Methyltransferase in Cancer. Front Immunol. 2015;6:487.

16. Ferry L, Fournier A, Tsusaka T, Adelmant G, Shimazu T, Matano S, et al. Methylation of DNA Ligase 1 by G9a/GLP Recruits UHRF1 to Replicating DNA and Regulates DNA Methylation. Molecular Cell. 2017;67:550-565.e5.

17. Wei L, Chiu DK-C, Tsang FH-C, Law C-T, Cheng CL-H, Au SL-K, et al. Histone methyltransferase G9a promotes liver cancer development by epigenetic silencing of tumor suppressor gene RARRES3. Journal of Hepatology. 2017;67:758-769.

18. Wozniak RJ, Klimecki WT, Lau SS, Feinstein Y, Futscher BW. 5-Aza-2'-deoxycytidinemediated reductions in G9A histone methyltransferase and histone $\mathrm{H} 3 \mathrm{~K} 9$ di-methylation levels are linked to tumor suppressor gene reactivation. Oncogene. 2007;26:77-90.

19. San José-Enériz E, Agirre X, Rabal O, Vilas-Zornoza A, Sanchez-Arias JA, Miranda E, et al. Discovery of first-in-class reversible dual small molecule inhibitors against G9a and DNMTs in hematological malignancies. Nature Communications. 2017;8:15424.

20. Nault J-C, Mallet M, Pilati C, Calderaro J, Bioulac-Sage P, Laurent C, et al. High frequency of telomerase reverse-transcriptase promoter somatic mutations in hepatocellular carcinoma and preneoplastic lesions. Nature Communications. 2013;4:2218.

21. Schulze K, Imbeaud S, Letouzé E, Alexandrov LB, Calderaro J, Rebouissou S, et al. Exome sequencing of hepatocellular carcinomas identifies new mutational signatures and potential therapeutic targets. Nat. Genet. 2015;47:505-511.

This article is protected by copyright. All rights reserved. 
22. Dauch D, Rudalska R, Cossa G, Nault J-C, Kang T-W, Wuestefeld T, et al. A MYC-aurora kinase A protein complex represents an actionable drug target in p53-altered liver cancer. Nature Medicine. 2016;22:744-753.

23. Rebouissou S, La Bella T, Rekik S, Imbeaud S, Calatayud A-L, Rohr-Udilova N, et al. Proliferation Markers Are Associated with MET Expression in Hepatocellular Carcinoma and Predict Tivantinib Sensitivity In Vitro. Clin. Cancer Res. 2017;23:4364-4375.

24. Rombouts K, Carloni V. Determination and Characterization of Tetraspanin-Associated Phosphoinositide-4 Kinases in Primary and Neoplastic Liver Cells. Methods Mol. Biol. 2016;1376:203-212.

25. Saito Y, Kanai Y, Nakagawa T, Sakamoto M, Saito H, Ishii H, et al. Increased protein expression of DNA methyltransferase (DNMT) 1 is significantly correlated with the malignant potential and poor prognosis of human hepatocellular carcinomas. Int. J. Cancer. 2003;105:527-532.

26. Mudbhary R, Hoshida Y, Chernyavskaya Y, Jacob V, Villanueva A, Fiel MI, et al. UHRF1 overexpression drives DNA hypomethylation and hepatocellular carcinoma. Cancer Cell. 2014;25:196-209.

27. Nault J-C, De Reynies A, Villanueva A, Calderaro J, Rebouissou S, Couchy G, et al. A Hepatocellular carcinoma 5-gene score associated with survival of patients after liver resection. Gastroenterology. 2013;145:176-187.

28. Boyault S, Rickman DS, de Reyniès A, Balabaud C, Rebouissou S, Jeannot E, et al. Transcriptome classification of HCC is related to gene alterations and to new therapeutic targets. Hepatology. 2007;45:42-52.

29. Hoshida Y, Nijman SMB, Kobayashi M, Chan JA, Brunet J-P, Chiang DY, et al. Integrative transcriptome analysis reveals common molecular subclasses of human hepatocellular carcinoma. Cancer Res. 2009;69:7385-7392.

30. Hsiao L-L, Dangond F, Yoshida T, Hong R, Jensen RV, Misra J, et al. A compendium of gene expression in normal human tissues. Physiological Genomics. 2001;7:97-104.

31. Giannelli G, Koudelkova P, Dituri F, Mikulits W. Role of epithelial to mesenchymal transition in hepatocellular carcinoma. Journal of Hepatology. 2016;65:798-808.

32. Hirata H, Sugimachi K, Komatsu H, Ueda M, Masuda T, Uchi R, et al. Decreased Expression of Fructose-1,6-bisphosphatase Associates with Glucose Metabolism and Tumor Progression in Hepatocellular Carcinoma. Cancer Res. 2016;76:3265-3276.

33. Vander Heiden MG, DeBerardinis RJ. Understanding the Intersections between Metabolism and Cancer Biology. Cell. 2017;168:657-669.

34. Wilson GK, Tennant DA, McKeating JA. Hypoxia inducible factors in liver disease and hepatocellular carcinoma: Current understanding and future directions. Journal of Hepatology. 2014;61:1397-1406.

This article is protected by copyright. All rights reserved. 
35. Casciello F, Al-Ejeh F, Kelly G, Brennan DJ, Ngiow SF, Young A, et al. G9a drives hypoxiamediated gene repression for breast cancer cell survival and tumorigenesis. Proc. Natl. Acad. Sci. U.S.A. 2017;114:7077-7082.

36. Klein A, Flugel D, Kietzmann T. Transcriptional Regulation of Serine/Threonine Kinase15 (STK15) Expression by Hypoxia and HIF-1. Mol. Biol. Cell. 2008;19:3667-3675.

37. Hay N. Reprogramming glucose metabolism in cancer: can it be exploited for cancer therapy? Nat Rev Cancer. 2016;16:635-649.

38. Roth KJ, Copple BL. Role of Hypoxia-Inducible Factors in the Development of Liver Fibrosis. Cell. Mol. Gastroenterol. Hepatol. 2015;1:589-597.

39. Moran-Salvador E, Mann J. Epigenetics and Liver Fibrosis. Cell. Mol. Gastroenterol. Hepatol. 2017;4:125-134.

40. Coulouarn C, Clément B. Stellate cells and the development of liver cancer: therapeutic potential of targeting the stroma. Journal of Hepatology. 2014;60:1306-1309.

41. Tan J, Yang X, Zhuang L, Jiang X, Chen W, Lee PL, et al. Pharmacologic disruption of Polycomb-repressive complex 2-mediated gene repression selectively induces apoptosis in cancer cells. Genes \& Development. 2007;21:1050-1063.

42. Purcell DJ, Khalid O, Ou C-Y, Little GH, Frenkel B, Baniwal SK, et al. Recruitment of coregulator G9a by Runx2 for selective enhancement or suppression of transcription. J. Cell. Biochem. 2012;113:2406-2414.

43. Dong C, Wu Y, Yao J, Wang Y, Yu Y, Rychahou PG, et al. G9a interacts with Snail and is critical for Snail-mediated E-cadherin repression in human breast cancer. J. Clin. Invest. 2012;122:1469-1486.

44. Avila MA, Berasain C, Torres L, Martin-Duce A, Corrales FJ, Yang H, et al. Reduced mRNA abundance of the main enzymes involved in methionine metabolism in human liver cirrhosis and hepatocellular carcinoma. J. Hepatol. 2000;33:907-914.

45. Huidobro C, Toraño EG, Fernández AF, Urdinguio RG, Rodríguez RM, Ferrero C, et al. A DNA methylation signature associated with the epigenetic repression of glycine Nmethyltransferase in human hepatocellular carcinoma. J. Mol. Med. 2013;91:939-950.

46. Li B, Qiu B, Lee DSM, Walton ZE, Ochocki JD, Mathew LK, et al. Fructose-1,6bisphosphatase opposes renal carcinoma progression. Nature. 2014;513:251-255.

47. Kluwe J, Wongsiriroj N, Troeger JS, Gwak G-Y, Dapito DH, Pradere J-P, et al. Absence of hepatic stellate cell retinoid lipid droplets does not enhance hepatic fibrosis but decreases hepatic carcinogenesis. Gut. 2011;60:1260-1268.

48. Jiang Y, Wang S, Zhao Y, Lin C, Zhong F, Jin L, et al. Histone H3K9 demethylase JMJD1A modulates hepatic stellate cells activation and liver fibrosis by epigenetically regulating peroxisome proliferator-activated receptor $\gamma$. FASEB J. 2015;29:1830-1841.

This article is protected by copyright. All rights reserved. 
49. Seki E, De Minicis S, Osterreicher CH, Kluwe J, Osawa Y, Brenner DA, et al. TLR4 enhances TGF-beta signaling and hepatic fibrosis. Nature Medicine. 2007;13:1324-1332.

50. de Thé H. Differentiation therapy revisited. Nat Rev Cancer. 2018;18:117-127.

Author names in bold designate shared co-first authorship.

\section{Figure legends}

Figure 1. G9a, DNMT1 and UHRF1 expression in human HCC. (A) G9a, DNMT1 and UHRF1 mRNA levels in normal, NT and T human liver tissues. (B) Spearman correlation analysis of $G 9 a$, DNMT1 and UHRF1 expression in tumoral liver tissue samples. (C) G9a, DNMT1 and UHRF1 gene expression in tumoral liver tissues from patients classified according to the 5-gene score, the G1 to G6 transcriptomic groups, the presence of macroscopic vascular invasion, the Edmonson Grade and the TNM score. (D) Post-operative survival of HCC patients according to G9a, DNMT1 and UHRF1 expression levels. NT: peritumoral liver tissue; T: tumoral liver tissue; DNMT: DNAmethyltransferase; UHRF1: ubiquitin-like with PHD and RING finger domains 1. TNM: tumor, node, metastasis.

\section{Figure 2. Expression and simultaneous targeting of G9a and DNMT1 in human HCC cell}

lines. (A) G9a, DNMT1 and UHRF1 gene expression in normal human liver tissues, NTs and human HCC cell lines (n=32). (B) G9a, DNMT1 and UHRF1 protein levels in primary normal human hepatocytes and HCC cell lines. Ponceau staining of membrane demonstrates equal loading. (C) Spearman correlation analysis of G9a, DNMT1 and UHRF1 mRNA levels in HCC cell lines. (D) Effects of simultaneous siRNA-mediated knockdown of $G 9 a$ and DNMT1 gene expression on cell growth. (E) Combination study of the growth inhibitory effects of G9a (BIX01294) and DNMT1 (decitabine) inhibitors in HepG2 and PLC/PRF5 cells. NT: peritumoral liver tissue; DNMT: DNA-methyltransferase; UHRF1: ubiquitin-like with PHD and RING finger domains 1 .

This article is protected by copyright. All rights reserved. 
Figure 3. Targeting of G9a and DNMT1 with the dual inhibitor CM-272 in human HCC cells in vitro and in vivo. (A) Chemical structure and $\mathrm{GI}_{50}$ values of $\mathrm{CM}-272$ in 32 human $\mathrm{HCC}$ cell lines. (B) H3K9me2, 5meC, G9a, DNMT1 and UHRF1 levels in HepG2 and PLC/PRF5 cells treated for $48 \mathrm{~h}$ with $\mathrm{CM}-272$ at its $\mathrm{GI}_{50}$ concentration for each cell line. Ponceau staining of histones and methylene blue staining of DNA are loading controls. (C) Colony formation assays in HepG2 and PLC/PRF5 cells treated with CM-272. (D) Effect of CM-272 on the growth of PLC/PRF5 cells as subcutaneous xenografts, or (E) as orthotopic xenografts in nude mice. Right panels: tumor weight in control (PBS) and CM-272-treated mice at the end of treatments. H3K9me2: dimethylated histone-3-lysine-9; 5meC: 5-methyl-cytosine. GI $_{50}$ : concentration inhibiting growth by $50 \%$.

Figure 4. CM-272 strongly influences HCC cells gene expression promoting a quiescent and differentiated phenotype. (A) Most relevant GO categories of genes undergoing changes in expression identified by microarray analysis in HepG2 cells treated with CM-272. (B) GSEA of Boyault and Hoshida datasets revealed that CM-272 downregulated genes enriched among signatures associated with more aggressive HCCs (subclass G1-G3 in Boyault, subclass S2 in Hoshida). Conversely, GSEA analysis of Hsiao gene-set shows upregulation of liver-specific genes upon CM-272 treatment. (C) Expression of E-CAD and other genes characteristic of the differentiated hepatocellular phenotype in HepG2 cells treated with CM-272 (400nM) for 48h. Right panel shows representative western blots of the indicated proteins in control and CM-272 treated HepG2 cells. (D) H3K9me2 qChIP analysis in the proximal promoter region of CYP7A1, FBP1 and GNMT in HepG2 cells treated with CM-272 (400nM) for 48h. Data are representative of three experiments performed in duplicates. (E) Left panel: DNA methylation analysis in $F B P 1$ promoter in control and CM-272 treated cells. Genomic DNA from normal human liver and the effect of decitabine on HepG2 cells were used as controls. Bands in lanes labeled "U" and "M" are PCR products amplified with unmethylation- and methylation-specific primers. Images are representative of three experiments performed in duplicates. Right panel: DNA methylation analysis by pyrosequencing of the $F B P 1$ gene region adjacent to the transcription start site This article is protected by copyright. All rights reserved. 
(TSS) in normal liver tissue, HepG2 cells and CM-272 treated HepG2 cells. (F) Left panel: glucose (2-deoxyglucose) uptake in control and CM-272 (400nM, 48h) treated HepG2 cells. Right panel: lactate production in equally treated HepG2 cells. Experiments were performed twice in triplicates. GO: gene ontology; GSEA: gene-set enrichment analysis; E-CAD: E-cadherin; CYP7A1: cholesterol 7 $\alpha$-hydroxylase; FBP1: fructose-1,6-bisphosphatase; GNMT: glycine-N-methyl transferase; MAT1A: methionine-adenosyltransferase 1A; H3K9me2: dimethylated histone-3lysine-9; qChIP: quantitative chromatin immunoprecipitation; MSP: methylation-specific PCR; TSS: transcription start site.

Figure 5. CM-272 inhibits the protumorigenic responses of HCC cells to hypoxia. (A) G9a protein levels in HepG2 cells under normoxia or hypoxia (24h). (B) Effect of CM-272 (400nM) on hypoxia-induced HepG2 cell growth. Cells were pretreated with CM-272 for $24 \mathrm{~h}$ and then kept in normoxic or hypoxic conditions for another 24h. (C) Effect of CM-272 (400nM) on the expression of key hypoxia-induced glycolytic genes. (D) Effect of CM-272 (400nM) on lactate production in HepG2 cells. (E) Effects of CM-272 (400nM), siRNA-mediated G9a expression knockdown (siG9a), and $G 9 a$ overexpression (pG9a), on hypoxia-induced $V E G F$ and TGF $\beta$ gene expression. GLUT-1: glucose transporter-1; HK2: hexokinase-2; GPI: glucose-6-phosphate isomerase; ALDOA: aldolase A; PGK1: phosphoglycerate kinase-1; PKM2: pyruvate kinase-M2; LDHA: lactate dehydrogenase-A; VEGF: vascular endothelial growth factor; TGF $\beta$ : transforming growth factor- $\beta$; Ctrl: control.

Figure 6. CM-272 inhibits HSC activation and fibrogenic responses to TGF $\beta$. (A) Effect of CM-272 on the growth of LX2 cells (48h treatment). (B) Most relevant GO categories of genes undergoing changes in expression identified by microarray analysis in LX2 cells treated with CM-272 (400nM) for 48h. (C) GSEA revealed that CM-272 upregulated genes are associated

This article is protected by copyright. All rights reserved. 
with retinol metabolism while it inhibited those involved in TGF $\beta$ activity. (D) Effect of CM-272 on the expression of genes associated with differentiated and quiescent HSCs. LX2 and primary hHSCs were treated with CM-272 (400nM) for 48h. (E) Left panel: H3K9me2 qChIP analysis in the proximal promoter region of PPAR $\gamma$ in LX2 cells treated with CM-272 (400nM) for 48h. Data are representative of three experiments performed in duplicates. Right panel: DNA methylation analysis in PPAR $\gamma$ promoter region in control, CM-272 and decitabine-treated LX2 cells. Bands in lanes labeled " $\mathrm{U}$ " and "M" are PCR products amplified with unmethylation- and methylationspecific primers. Images are representative of three experiments performed in duplicates. (F) Effect of CM-272 on the expression of TGF $\beta$ target genes. LX2 and hHSCs were pretreated with CM-272 (400nM) for $24 \mathrm{~h}$ and then treated with TGF $\beta(5 \mathrm{ng} / \mathrm{mL})$ for $24 \mathrm{~h}$ more as indicated. GO: gene ontology; GSEA: gene-set enrichment analysis; hHSC: human hepatic stellate cells; PPAR $\gamma$ : peroxisome proliferator-activated receptor- $\gamma$ : BAMBI: BMP and activin membrane-bound inhibitor; LRAT: lecithin-retinol acyltransferase; $\alpha$-SMA: $\alpha$-smooth muscle actin; COLI $\alpha 1$ : procollagen I- $\alpha-1$; TGF $\beta$ : transforming growth factor- $\beta$; SKIL: SKI-like proto-oncogene; TAGLN: transgelin; LOX: lysyl-oxidase. MSP: methylation-specific PCR

Figure 7. CM-272 potently inhibits the growth of HSC-driven HCC xenografts in mice. (A) Growth rate of subcutaneous tumors formed by PLC/PRF5 cells injected alone or in combination with LX2 cells in nude mice. (B) Effect of CM-272 treatment on the growth of PLC/PRF5+LX2 subcutaneous tumors in nude mice. Right panel shows tumor weight at the end of experiments. (C) Quantitation of vascular density assessed as CD31 immunostaining in PLC/PRF5+LX2 xenograft tumors from control (PBS) and CM-272 treated mice. (D) Western blot analysis of G9a, HK2, GNMT and FBP1 expression in PLC/PRF5+LX2 xenograft tumors from control (PBS) and CM-272 treated mice. Representative blots are shown. PBS: phosphatebuffered saline; HK2: hexokinase-2; GNMT: glycine-N-methyl transferase; FBP1: fructose-1,6bisphosphatase.

This article is protected by copyright. All rights reserved. 
Figure 8. Dual targeting of G9a and DNMT1 in HCC treatment. HCC: hepatocellular carcinoma; DNMT1: DNA-methyltransferase; UHRF1: ubiquitin-like with PHD and RING finger domains 1.

Acknowledgments. The technical support of Dr. MJ Moreno (Department of Physiology, University of Navarra, Pamplona, Spain) with the glucose uptake experiments. The help of Dr. A Pardo-Saganta (Regenerative Medicine Program, CIMA-University of Navarra, Pamplona, Spain) with immunohistological analyses is also acknowledged. We thank the French Centre de Ressources Biologiques (CRB) for liver tumors, Dr Julien Calderaro and Pr Paulette Bioulac-Sage for tumor collections at Créteil (CRB Centre Hospitalier Universitaire Henri Mondor) and Bordeaux (Tumorotheque Centre Hospitalier Universitaire Bordeaux) hospitals, respectively.

This article is protected by copyright. All rights reserved. 
A
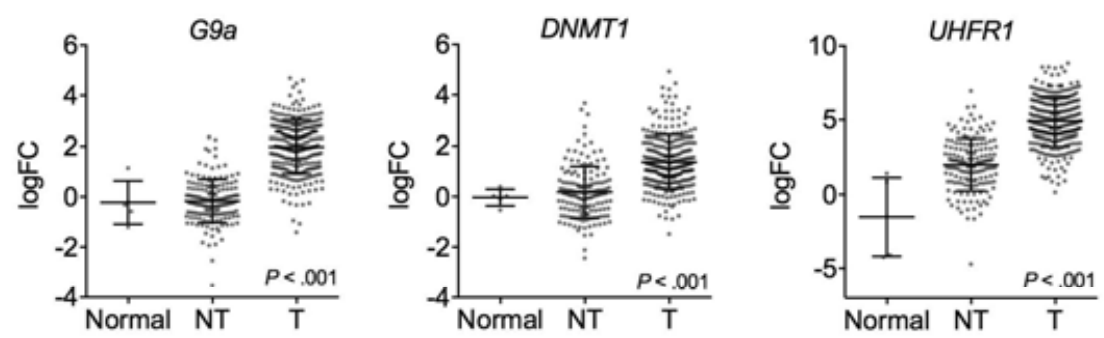

B
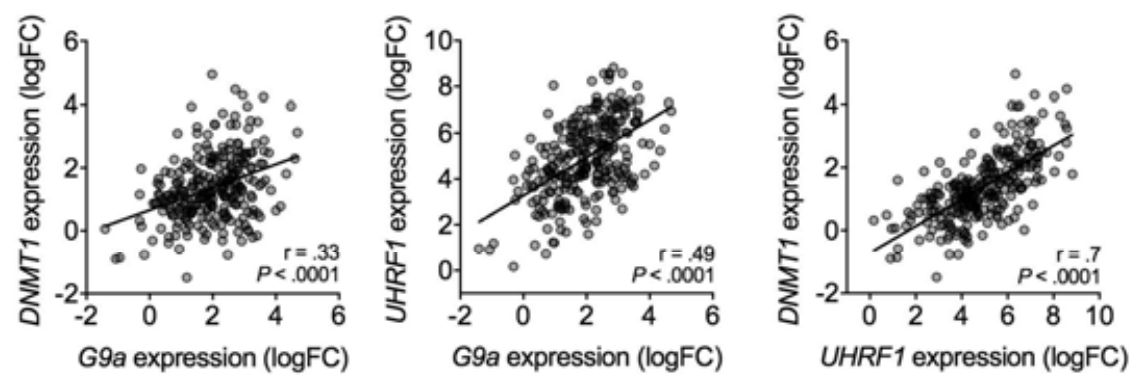

C
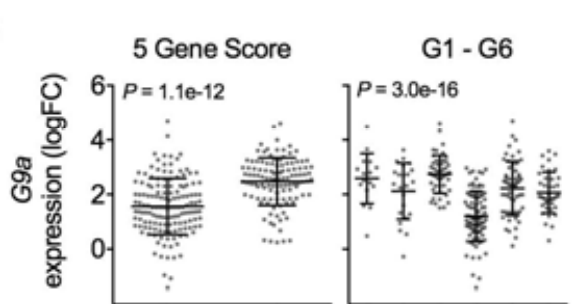

Macroscopic

Edmonson Grade TNM
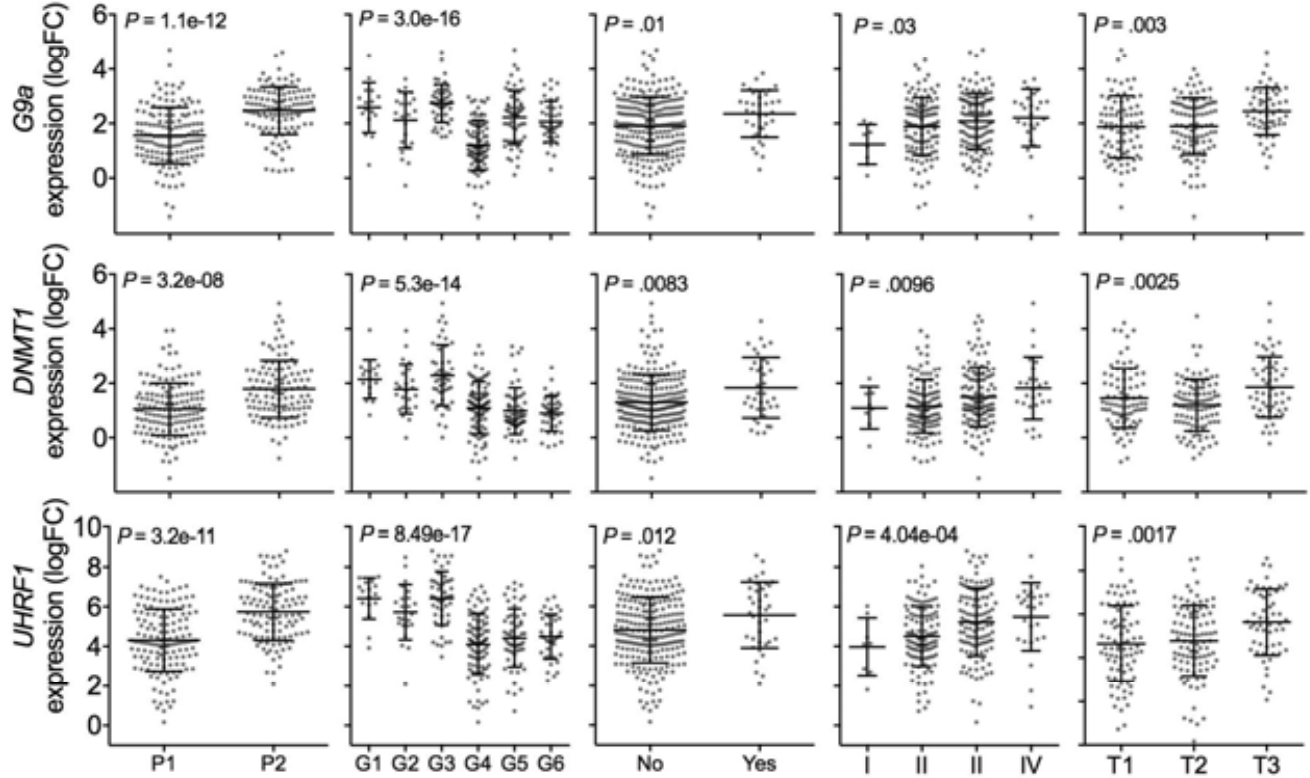

D
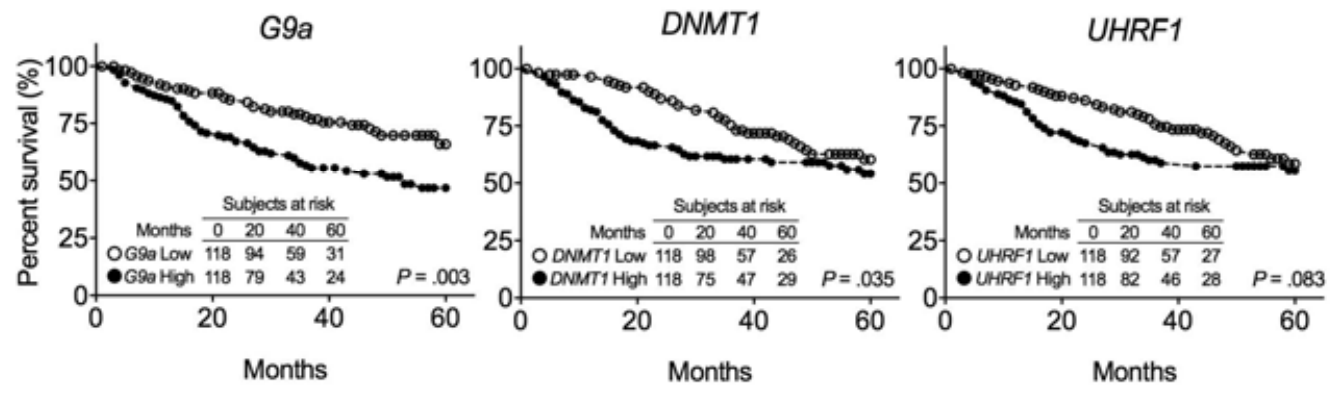

Figure 1

This article is protected by copyright. All rights reserved. 
A
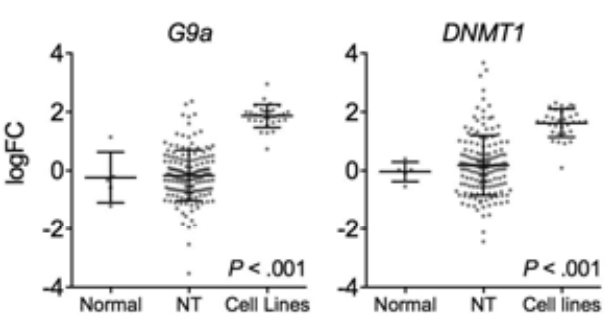

B
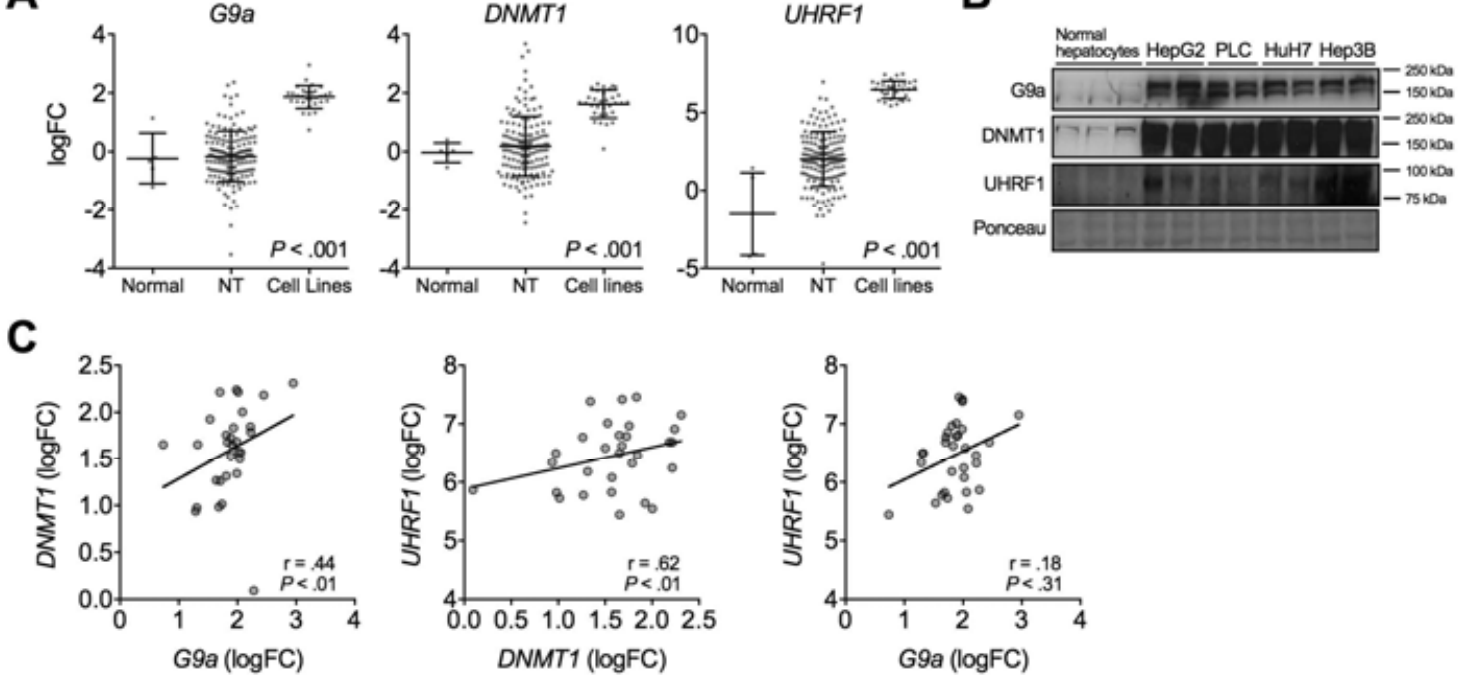

D

E
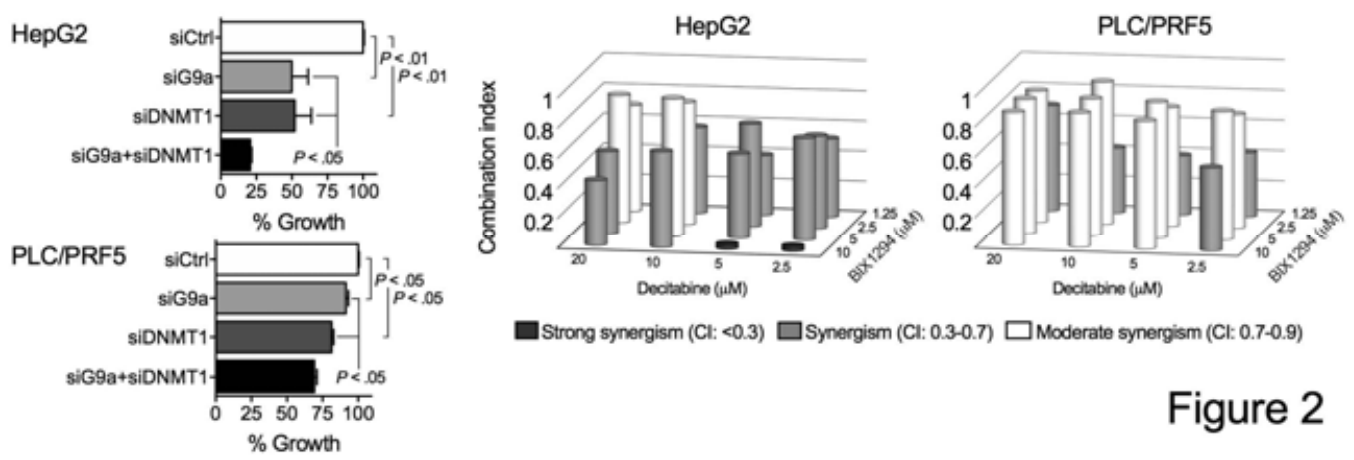

$\square$ Strong synergism (Cl: <0.3) $\square$ Synergism (Cl: 0.3-0.7) $\square$ Moderate synergism (Cl: 0.7-0.9)

Figure 2

This article is protected by copyright. All rights reserved. 

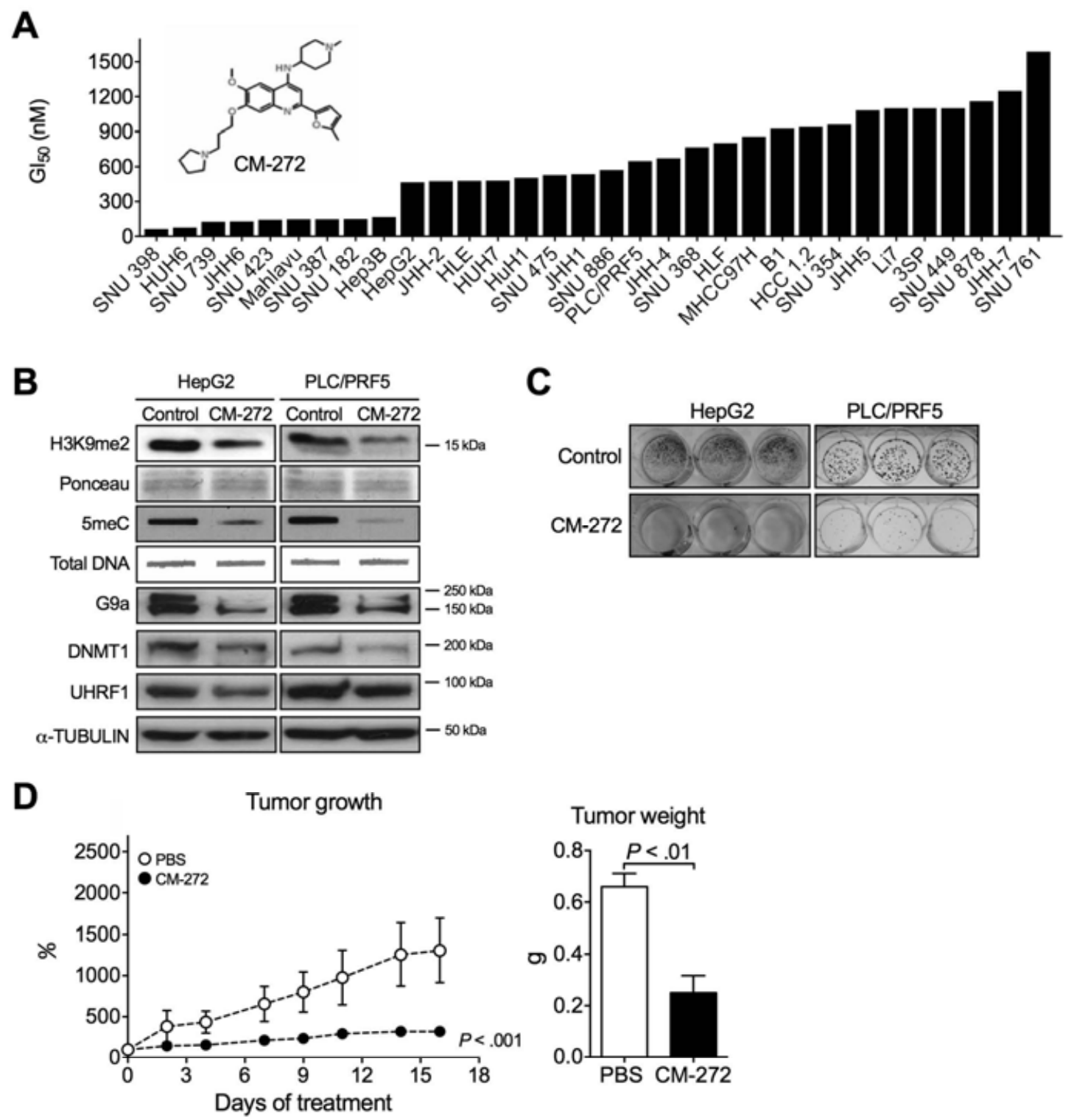

$\mathbf{E}$

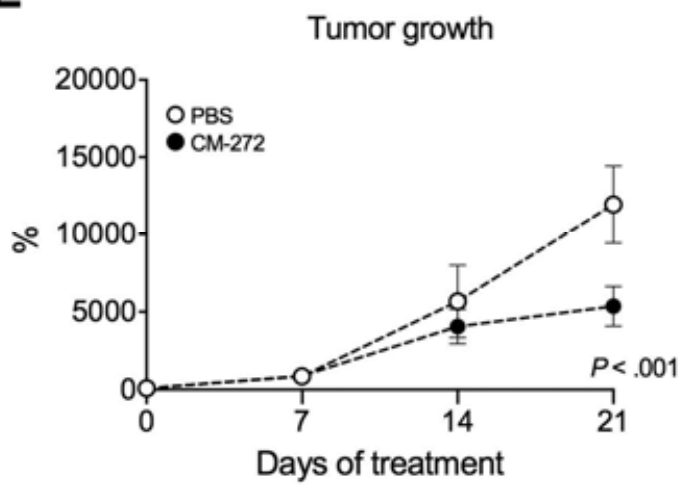

Tumor weight

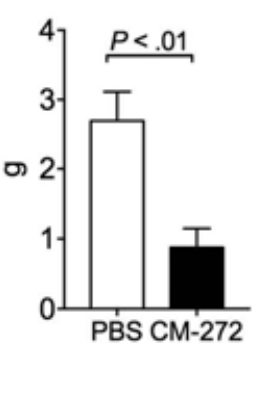

Figure 3

This article is protected by copyright. All rights reserved. 
A

GO analysis

Response to extracellular stimulus

Regulation of signaling

49

Regulation of cell communication Wound healing

Regulation of response to stimulus 60

Growth factor activity

Cell proliferation 81

Extracellular space 22

$\begin{array}{llllllllll}0.0 & 0.5 & 1.0 & 1.5 & 2.0 & 2.5 & 3.0 & 3.5\end{array}$

$-\log (P$ value $)$

B

BOYAULT_LIVER_CANCER_SUBCLASS_G123_UP HOSHIDA_LIVER_CANCER_SUBCLASS_S2

HSIAO_LIVER_SPECIFIC_GENES
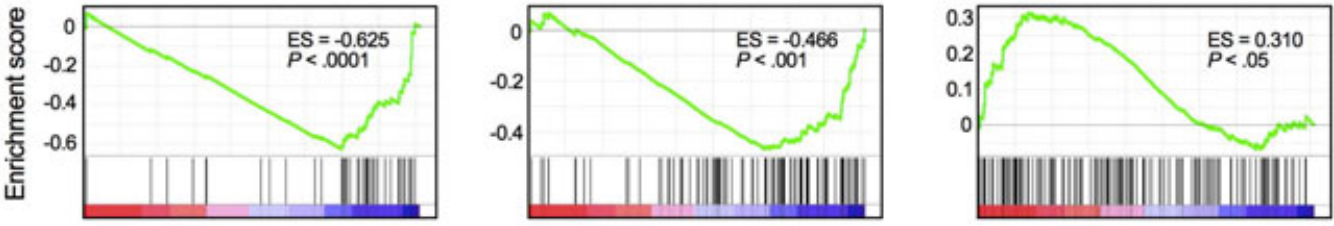

C
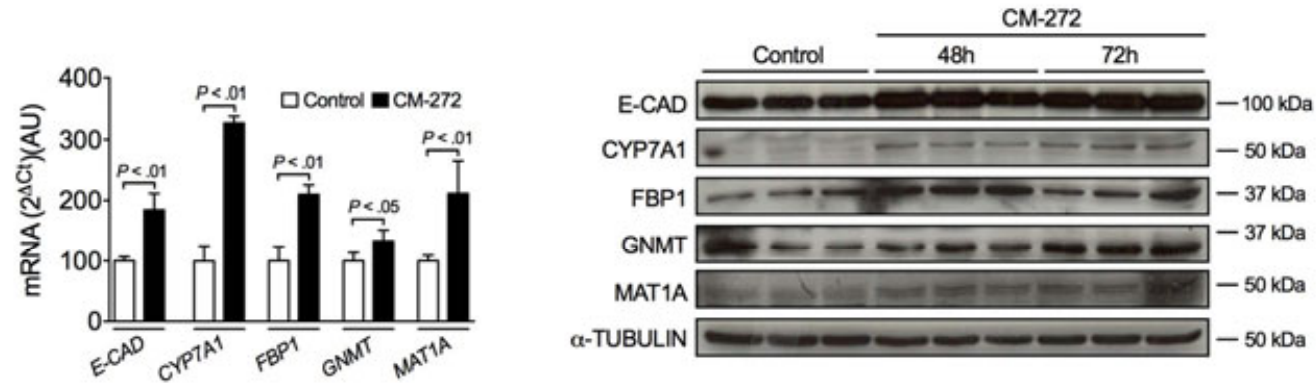

D

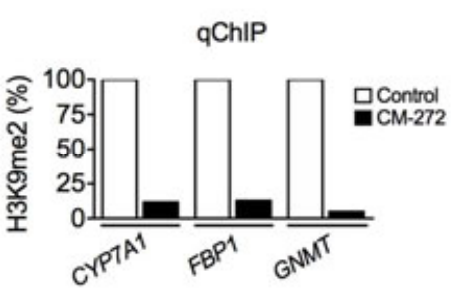

E

MSP FBP1

Pyrosequencing FBP1

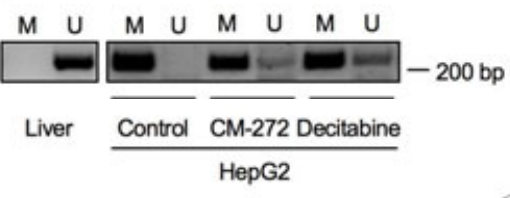

TSS

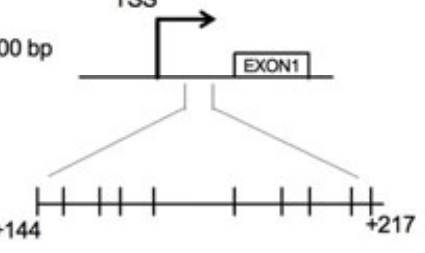

$\mathbf{F}$
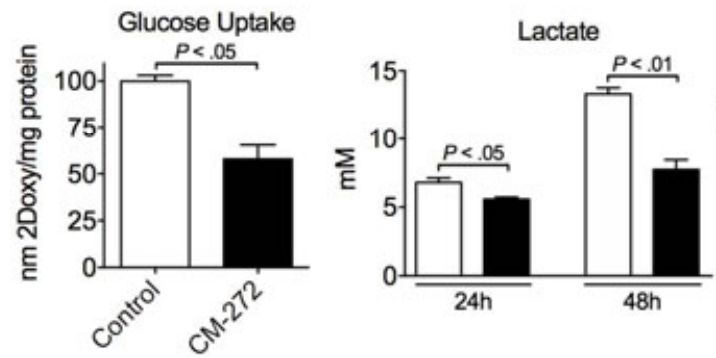

口Control

- $\mathrm{CM}-272$

$$
\text { the }
$$

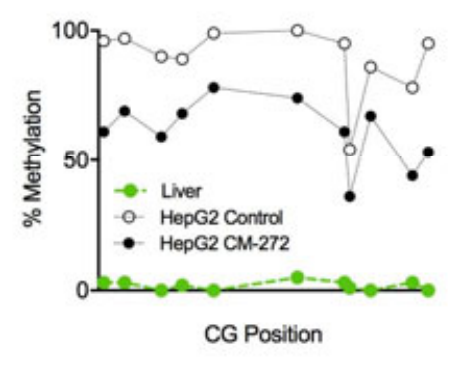

Figure 4

This article is protected by copyright. All rights reserved. 

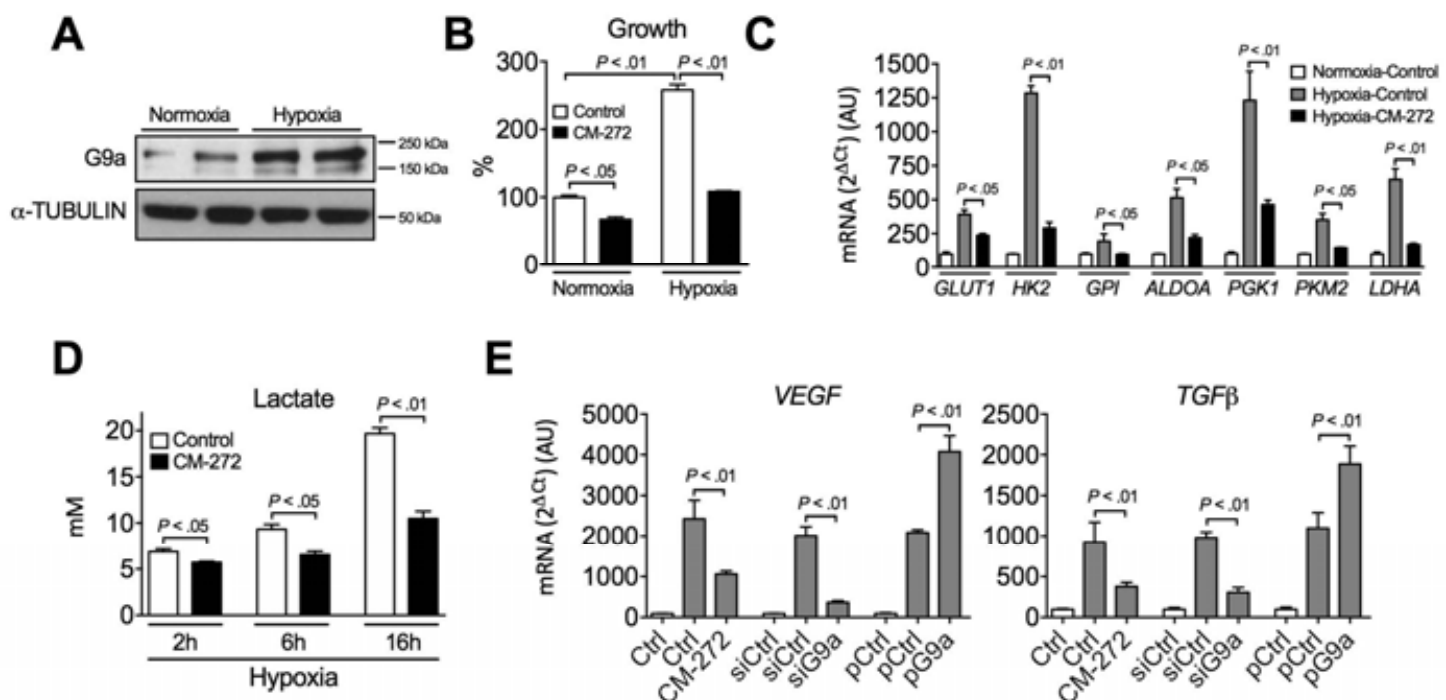

E

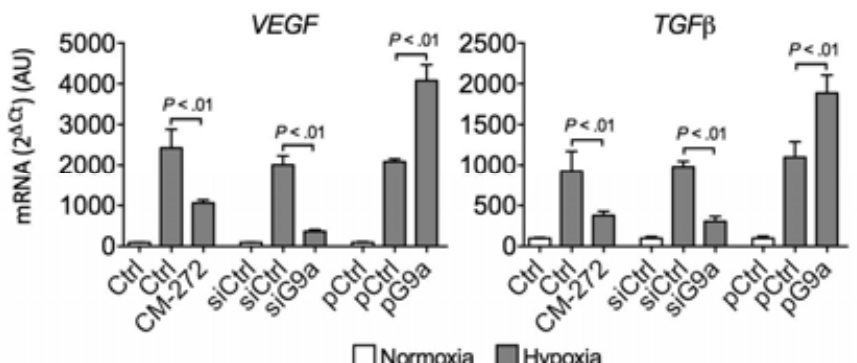

Figure 5

This article is protected by copyright. All rights reserved. 
A

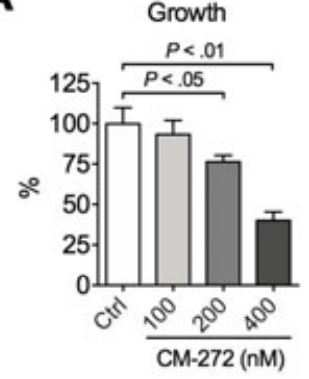

B

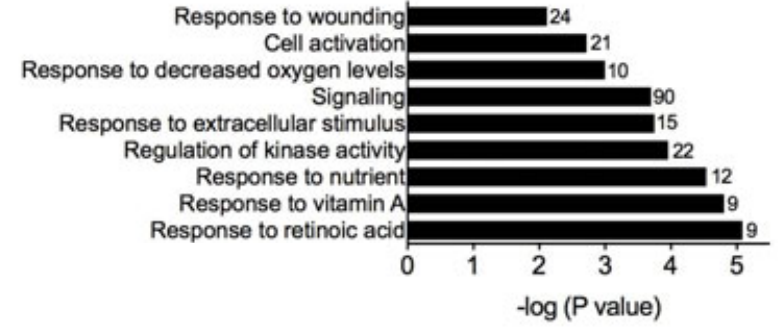

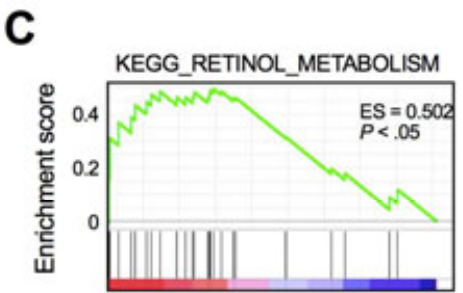

REACTOME SIGNALING BY TGF_BETA_RECEPTOR_COMPL̄EX
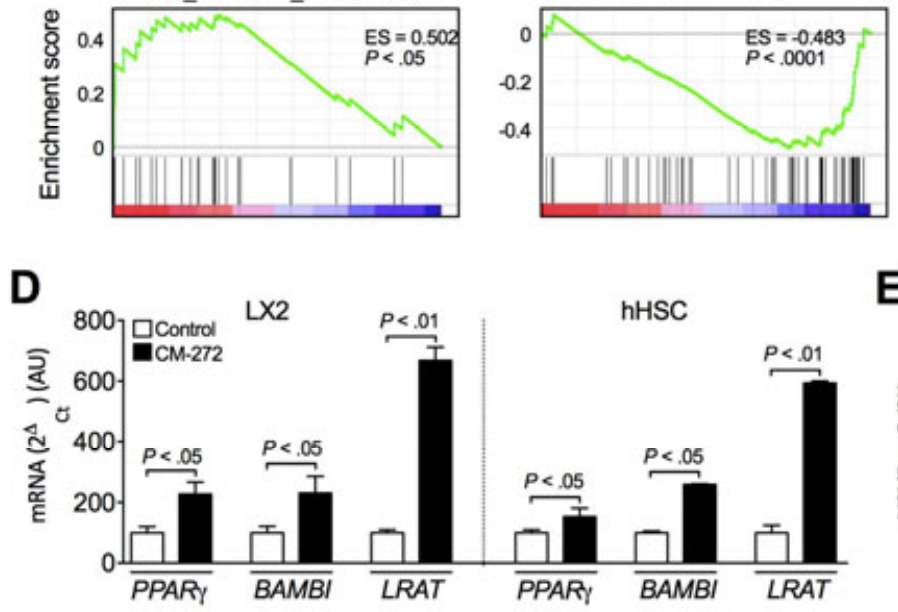

$\mathbf{F}$

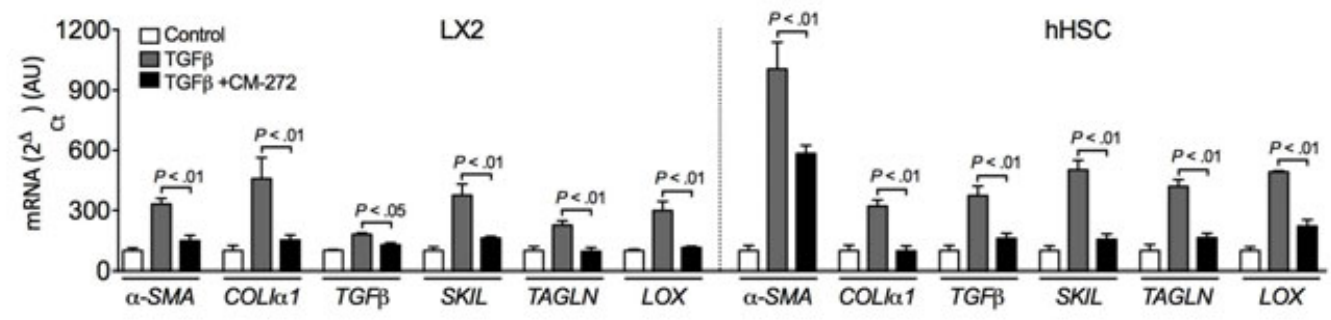

Figure 6

This article is protected by copyright. All rights reserved. 
A

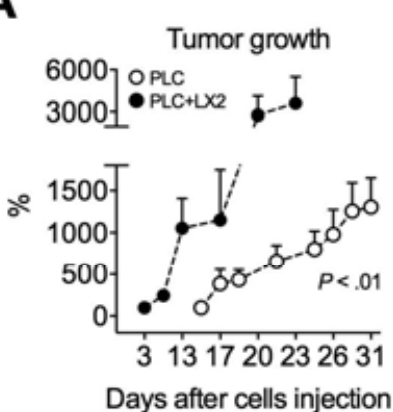

B

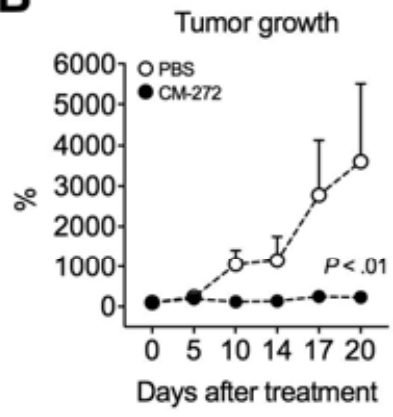

D

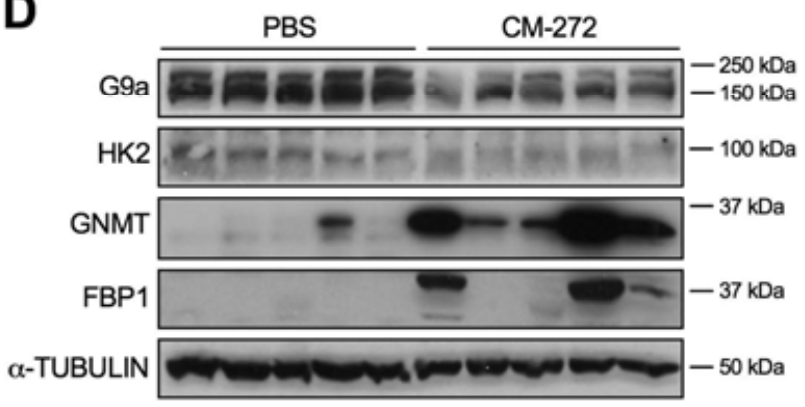

C
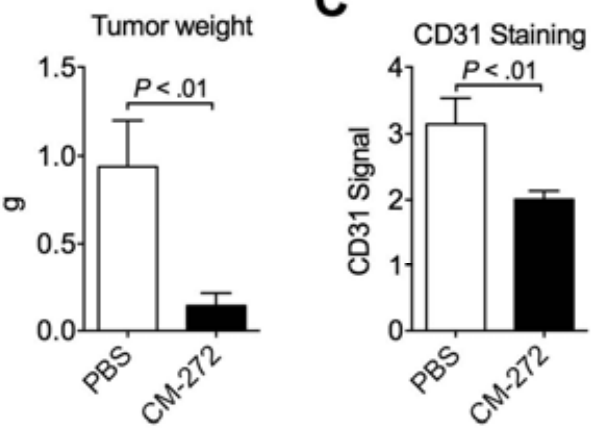

Figure 7

This article is protected by copyright. All rights reserved. 


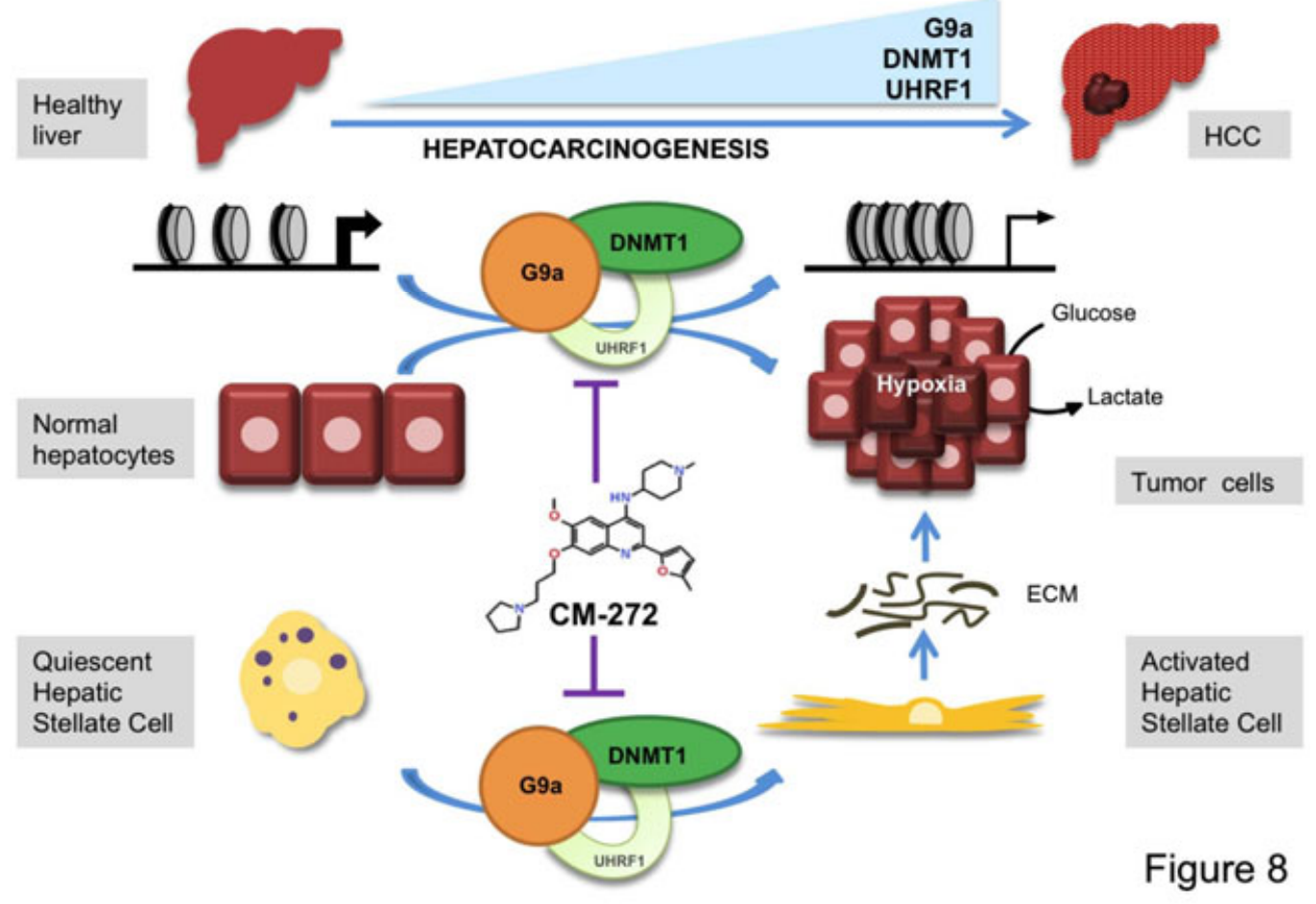

This article is protected by copyright. All rights reserved. 